\title{
Mullite/Mo interfaces formed by intrusion bonding
}

J. F. BARTOLOMÉ ${ }^{1}$, M. DÍAZ ${ }^{1}$, J. S. MOYA ${ }^{1}$, E. SAIZ ${ }^{2}$, AND A. P. TOMSIA ${ }^{2}$

${ }^{1}$ Instituto de Ciencia de Materiales-CSIC

Cantoblanco

28049 Madrid

Spain

${ }^{2}$ Materials Sciences Division

Lawrence Berkeley National Laboratory

Materials Sciences Division

Berkeley, CA 94720 USA

April, 2003

This work has been supported by the Ministry of Science and Technology, Spain, under project number MAT2000-1354. José F. Bartolomé has been supported by the "Consejería de Educación y Cultura de la Comunidad de Madrid," Spain. The authors thank Robert A. Marks for experimental assistance. E. Saiz's and A. P. Tomsia's work was supported by the Director, Office of Science, Office of Basic Energy Sciences, Division of Materials Sciences and Engineering, of the U.S. Department of Energy under Contract No. DE-AC03-76SF00098. 


\title{
Mullite/Mo interfaces formed by intrusion bonding
}

Jose F. Bartolome ${ }^{1}$, Marcos. Díaz ${ }^{1}$, Jose S. Moya ${ }^{1}$ Eduardo Saiz ${ }^{2}$ and Antoni P. Tomsia ${ }^{2}$

${ }^{1}$ Instituto de Ciencia de Materiales-CSIC, Cantoblanco, 28049 Madrid, Spain

${ }^{2}$ Lawrence Berkeley National Laboratory, Berkeley, CA 94720, USA

\begin{abstract}
The microstructure and strength of Mo/mullite interfaces formed by diffusion bonding at $1650^{\circ} \mathrm{C}$ has been analyzed. Interfacial metal-ceramic interlocking contributes to flexural strength of $\sim 140 \mathrm{MPa}$ as measured by 3 point bending. Saturation of mullite with $\mathrm{MoO}_{2}$ does not affect the interfacial strength.
\end{abstract}

Keywords: diffusion bonding, microstructure, fracture, metal, oxide

\section{Introduction}

Ceramic-metal composites combine properties that are unobtainable in single-phase materials. The nature of the ceramic-metal interface is critical in determining the stability and mechanical properties of the composite [1-4]. Bimaterial interfaces have been shown to provide toughening in composite materials [4], either through weak bonding between the brittle matrix and the ductile phase (providing crack deflection) or through strong bonding between these phases (promoting plastic deformation of the metallic phase). Understanding and controlling the mechanical behavior of interfaces formed between ceramics and metals is therefore important for the mechanical reliability of ceramic-metal composites.

The importance of oxygen activity for adhesion at metal-oxide interfaces has been long recognized, and it has been observed that the thermodynamic work of adhesion increases with the oxygen activity [5]. It has also been proposed that optimum adhesion can be achieved if the ceramic is saturated with the substrate metal oxide in equilibrium with the metal [6]. This research was initiated to test the hypothesis that mullite saturated with Mo oxide should provide 
better adhesion to molybdenum than in pure condition. We have investigated the influence of $\mathrm{MoO}_{2}$ in solid solution in mullite $\left(3 \mathrm{Al}_{2} \mathrm{O}_{3} \cdot 2 \mathrm{SiO}_{2}\right)$ on the interfacial strength of $\mathrm{Mo} / \mathrm{mullite}$ joints prepared by diffusion bonding.

Mullite has long been recognized for its excellent resistance to creep and thermal shock in refractories [7-9]. Molybdenum was chosen because of its high melting point $\left(2610^{\circ} \mathrm{C}\right)$ and its thermal expansion coefficient $\left(\alpha_{\mathrm{Mo}}=5.75 \times 10^{-6}{ }^{\circ} \mathrm{C}^{-1}\right.$ at $\left.1000^{\circ} \mathrm{C}\right)$, which is very close to that of mullite $\left(\alpha_{\text {Mull }}=5.13 \times 10^{-6}{ }^{\circ} \mathrm{C}^{-1}\right.$ at $\left.1000^{\circ} \mathrm{C}\right)$. The residual thermal stresses resulting from thermal expansion mismatch are thus expected to be very small. Additionally, $\mathrm{MoO}_{2}$, mullite, and Mo are compatible in solid state at a temperature interval ranging from $\mathrm{RT}$ to $1650^{\circ} \mathrm{C}$ [4]. A solid solution of $\sim 4 \mathrm{wt} \%$ of $\mathrm{MoO}_{2}$ in mullite was determined at $1650^{\circ} \mathrm{C}$, and no reaction phases at the interface between mullite and molybdenum were observed [4]. Moreover, molybdenum is considered to be a model refractory metal, resistant to corrosion from most types of molten glasses and chemical reagents (except for oxidizing acids [8]).

\section{Experimental}

The following commercially available powders have been used: (1) Mullite (Scimarek Ltd., Japan) with an average particle size of $1.5 \mu \mathrm{m}$, specific surface area of $7 \mathrm{~m}^{2} / \mathrm{g}$, and chemical analysis (wt\%) as follows: $\mathrm{Al}_{2} \mathrm{O}_{3}$ (71.5), $\mathrm{SiO}_{2}$ (27.3), $\mathrm{Na}_{2} \mathrm{O}$ (0.02), $\mathrm{MgO}(0.04), \mathrm{CaO}(0.07)$ and $\mathrm{Fe}_{2} \mathrm{O}_{3}$ (0.05); and (2) $99.9 \% \mathrm{MoO}_{2}$ (Aldrich Chemical Company, USA), with an average particle size of $1 \mu \mathrm{m}$.

To obtain the mullite- $\mathrm{MoO}_{2}$ composites, we prepared a suspension of $50 \mathrm{wt} \%$ solid content (using ethyl alcohol as liquid media) with $92 \mathrm{wt} \%$ of mullite and $8 \mathrm{wt} \%$ of $\mathrm{MoO}_{2}$. The mixture was homogenized by milling with zirconia balls in polyethylene containers at $150 \mathrm{rpm}$ for 18 
hours and then dried at $65^{\circ} \mathrm{C}$ for 24 hours. The resulting powders were milled in an agate mortar and then sieved to a particle size $\leq 35 \mu \mathrm{m}$. Finally, the powders were pressed isostatically at 200 $\mathrm{MPa}$, and the resulting compact was sintered in vacuum $\left(5 \times 10^{-3} \mathrm{~Pa}\right)$ at $1650^{\circ} \mathrm{C}$ for 1 hour, with a heating and cooling rate of $10^{\circ} \mathrm{C} / \mathrm{min}$. It is expected that under these conditions the mullite will be saturated with $\mathrm{MoO}_{2}$ [4]. A similar experimental procedure was used to obtain pure mullite compacts.

The resulting dense ( $>99 \%$ theoretical) cylinders ( $25 \mathrm{~mm}$ in diameter, $35 \mathrm{~mm}$ in length) were cut with a diamond saw through a plane parallel to the circular section, and the bonding surface was polished down to $1 \mu \mathrm{m}$. Prior to bonding, the samples were ultrasonically cleaned with acetone and ethanol for 10 minutes each. Sandwich-like samples were prepared by placing 100 $\mu \mathrm{m}$ thick Mo foil (JM Johnson Matthey Electronics, USA) between two ceramic cylinders. Joining was performed at $1650^{\circ} \mathrm{C}$ in a graphite hot press under vacuum $\left(\sim 10^{-3} \mathrm{~Pa}\right)$ with the metal foil perpendicular to the pressing directions. The temperature was increased at a rate of $5^{\circ} \mathrm{C} / \mathrm{min}$, with the heating cycle occasionally interrupted to maintain the pressure below $10^{-3} \mathrm{~Pa}$. A thin BN film was deposited on the top and bottom surfaces of the samples to avoid reactions with the graphite pistons. We applied the full axial pressure of $10 \mathrm{MPa}$ at $1650^{\circ} \mathrm{C}$.

To study the adherence of the ceramic-metal interface, we qualitatively evaluated the relative crack resistance by indentation. Vickers indentations on the interfaces were performed in air on polished cross sections, using loads of up to $50 \mathrm{~kg}$. Flexural strength of the monolithic mullite and mullite- $\mathrm{MoO}_{2}$ composites and the bonded samples was evaluated using a three-point bending test at room temperature. The test was performed with prismatic bars $(45 \times 3 \times 3 \mathrm{~mm})$, using a $40 \mathrm{~mm}$ span and a crosshead speed of $0.5 \mathrm{~mm} \mathrm{~min}^{-1}$. For the diffusion-bonded specimens, the bars were cut perpendicular to the ceramic-metal interfaces, with the tensile surface polished 
down to $10 \mu \mathrm{m}$. The reported strengths represented the mean and standard deviation of at least 10 specimens and were calculated from the load at failure, using standard relationships derived for monolithic elastic materials.

The microstructures of sandwich specimens were studied on diamond-polished cross sections cut perpendicular to the planes of the joining interface and polished down to $1 \mu \mathrm{m}$. The cross sections were examined by reflected-light optical microscopy and scanning electron microscopy (SEM). After the three-point bending test, the fracture surfaces were analyzed by SEM.

\section{Results and discussion}

Figure 1 shows scanning micrographs that reveal the microstructures of the mullite and mullite- $\mathrm{MoO}_{2}$ composites. These composites were obtained by cold isostatic pressing and sintering in vacuum at $1650^{\circ} \mathrm{C}$ for 1 hour. In the mullite- $\mathrm{MoO}_{2}$ composites (Figure $1 \mathrm{~b}$ ), the $\mathrm{MoO}_{2}$ grains are located in the grain boundary of the mullite matrix. The microstructure of the cross sections of mullite/molybdenum and mullite- $\mathrm{MoO}_{2} /$ molybdenum samples, cut perpendicular to the planes of the joining interfaces, are shown in Figure $2 \mathrm{a}$ and $2 \mathrm{~b}$, respectively. In both cases, the metal foil adheres to the ceramic without any interfacial reaction product, as can be expected from the positive free energy for the possible reactions [10]:

$$
\begin{array}{ll}
3 \mathrm{Al}_{2} \mathrm{O}_{3} \cdot 2 \mathrm{SiO}_{2}+\mathrm{Mo} \rightarrow 3 \mathrm{Al}_{2} \mathrm{O}_{3}+2 \mathrm{MoO}_{2}+2 \mathrm{Si} & \Delta \mathrm{G} \approx 648 \mathrm{KJ} / \mathrm{mol} \\
3 \mathrm{Al}_{2} \mathrm{O}_{3} \cdot 2 \mathrm{SiO}_{2}+6 \mathrm{Mo} \rightarrow 3 \mathrm{Al}_{2} \mathrm{O}_{3}+2 \mathrm{Mo}_{3} \mathrm{Si}+2 \mathrm{O}_{2}\{\mathrm{~g}\} & \Delta \mathrm{G} \approx 953 \mathrm{KJ} / \mathrm{mol}
\end{array}
$$

The mullite intrudes into the asperities of the molybdenum foil and can be observed filling the Mo grain boundary grooves at the interface. The grooves form in order to achieve complete local equilibrium of the interfacial forces at the groove root and grow by diffusion (volume or interfacial) or solution/precipitation. Because the uniaxial pressure value is well below the high 
temperature compressive yield strength of Mo [11], no decrease in thickness in the metal layer is observed. In the mullite- $\mathrm{MoO}_{2} /$ molybdenum case, grain boundary sliding and cavitation phenomena in the molybdenum foil (Figure $2 b$ ) can be observed. It is well known that the fracture strength of molybdenum depends strongly on factors such as grain boundary character and impurity segregation. Kumar and Eyre [12] demonstrated that under certain conditions, extremely small amounts of oxygen (about $6 \mathrm{ppm}$ ) could cause grain-boundary embrittlement.

The equilibrium oxygen partial pressure for the reaction:

$\mathrm{Mo}+\mathrm{O}_{2} \rightarrow \mathrm{MoO}_{2}$

is $\sim 10^{-7}$ atm at $1650^{\circ} \mathrm{C}[10]$. When both molybdenum and molybdenum oxide are present reaction [3] can set the oxygen activity at the metal-ceramic interface. However, this oxygen activity is well above the activity present inside the graphite hot-press during bonding. The molybdenum oxide grains inside the mullite ceramic remain encapsulated from the atmosphere and due to faster atomic exchange, the oxide grains at the metal/ceramic interface can lose the oxygen and transform partially or completely to metallic molybdenum (Figure 3). The solubility of oxygen in bulk molybdenum is very low $\left(\sim 3 \mathrm{ppm}\right.$ at $\left.1650^{\circ} \mathrm{C}[13]\right)$. The oxygen has ample possibility to diffuse through molybdenum grain boundaries and promote intergranular brittleness. Since diffusion bonding is a pressure-assisted technique at high temperature, grain boundary sliding can occur, leading to local tensile stresses. When these stresses exceed the applied pressure, some cavity nucleation and coalescence can develop in the metal foil (on account of grain boundary sliding), causing stress concentrations at precipitates in the grain boundaries. Cavities will then develop at the precipitates whenever plastic flow or diffusion is not fast enough to prevent it. In the mullite/Mo diffusion bonding, the absence of $\mathrm{MoO}_{2}$ lowers the oxygen impurity levels at grain boundaries of the molybdenum foil. This would have the 
beneficial effect of suppressing grain boundary segregation and grain boundary precipitation of molybdenum oxide, which significantly weakens the grain boundaries.

The flexural strength values of the mullite and mullite- $\mathrm{MoO}_{2}$ composites were found to be very similar, $325 \pm 10 \mathrm{MPa}$ and $335 \pm 10 \mathrm{MPa}$, respectively. The interfacial fracture strength between the molybdenum foil and the mullite and mullite- $\mathrm{MoO}_{2}$ composite, measured by 3-point bending, was found to be $140 \pm 10 \mathrm{MPa}$ and $136 \pm 16 \mathrm{MPa}$ respectively. The fracture occurred at the ceramic-metal interface, and all the specimens broke with a linear load-deflection curve. The lack of difference in interfacial fracture strength is somewhat surprising, as according to previous theories the mullite saturated with $\mathrm{MoO}_{2}$ should form stronger bonds.[6] It may be concluded that oxygen content (or $\mathrm{MoO}_{2}$ ) does not appreciably affect the mullite/Mo adhesion, but it alters the microstructure and properties of the molybdenum interlayer. Additionally, the extensive metal/ceramic intrusion and interlocking can contribute to the strength of the joints by providing a mechanical bond.

Valuable information concerning the bonding process and joint failure mechanisms can be obtained from the fracture surfaces of the ceramic-metal interfaces (shown in Figure 5). Ridges were apparent on the mullite and mullite- $\mathrm{MoO}_{2}$ side of the fracture surface, with spacings comparable to the grain size in the metal. These ridges are believed to correspond to the intrusion of mullite at interfacial molybdenum grain boundary grooves. In parallel, similar impressions were evident on the molybdenum side of the fracture surface between molybdenum and the mullite, corresponding to mullite grains.

Because diffusion bonding is usually performed at temperatures wherein the metal may undergo plastic deformation. Metal intrusion along the grain boundaries of the ceramic during hot pressing has been described for many ceramic-metal systems (e.g., $\mathrm{Al}_{2} \mathrm{O}_{3} / \mathrm{Ni}, \mathrm{Al}_{2} \mathrm{O}_{3} / \mathrm{Cu}$, 
$\mathrm{Al}_{2} \mathrm{O}_{3} / \mathrm{Fe}$ [4], $\mathrm{ZrO}_{2} / \mathrm{Ni}$ [14]), but there very limited reports of ceramic penetration into metal during the bonding process [15]. The reason for this lack of information may be that usually the bonding temperatures reported in the literature are relatively low compared to the melting point of the ceramic. In our experiments, we used a stiff refractory metallic interlayer at a bonding temperature that is $\sim 90 \%$ of the melting point of mullite $\left(\sim 1800^{\circ} \mathrm{C}\right)$. At this temperature fast diffusion in both materials and at the interface contributes to the rapid growth of interfacial grain boundary grooves and plastic deformation of mullite helps to fill the interfacial asperities and achieve a more extensive contact at the metal/ceramic interface.

\section{Conclusions}

Mullite and mullite $/ \mathrm{MoO}_{2}$ ceramics were joined by (solid state diffusion bonding) hot pressing at $1650^{\circ} \mathrm{C}$, using a Mo metal interlayer. For all samples the results indicate strong ceramic-metal bonding $\left(\sigma_{\mathrm{f}} \approx 140 \mathrm{MPa}\right)$ with extensive interlocking. This interlocking result from mullite intrusion into the grain boundaries of a molybdenum metal sheet. The presence of $\mathrm{MoO}_{2}$ in mullite does not affect the final bond strength at room temperature. However, in the mullite- $\mathrm{MoO}_{2} / \mathrm{Mo}$ couples, the oxygen diffuses through the molybdenum grain boundaries, promoting the nucleation and coalescence of intergranular cavities (caused by grain boundary sliding during the bonding process) that could result in Mo enbrittlement.

\section{Acknowledgements}

This work has been supported by the Ministry of Science and Technology, Spain, under project number MAT2000-1354. José F. Bartolomé has been supported by the "Consejería de Educación y Cultura de la Comunidad de Madrid," Spain. The authors thank Robert A. Marks for experimental assistance. E. Saiz's and A. P. Tomsia's work was supported by the Director, 
Office of Science, Office of Basic Energy Sciences, Division of Materials Sciences and Engineering, of the U.S. Department of Energy under Contract No. DE-AC03-76SF00098. 


\section{References}

[1] Rühle, M., Structure and Composition of Metal/Ceramic Interfaces. Key Engineering Materials, 1996, 116, 1-40

[2] Mader, W. \& Rühle. M., Electron microscopy studies of defects at diffusion-bonded $\mathrm{Nb} / \mathrm{Al}_{2} \mathrm{O}_{3}$ interfaces. Acta Metall., 1989; 37, 853-866.

[3] Evans, A. G., Lu, M. C., Schmauder, S. \& Rühle, M., Some aspects of the mechanical strength of ceramic/metal bonded systems. Acta Metall., 1986, 34, 1643-1655.

[4] Bartolomé, J. F., Díaz, M., Requena, J., Moya, J. S. \& Tomsia, A. P., Mullite/molybdenum ceramic-metal composites, Acta Mater, 1999, 47, 3891-3899.

[5] Saiz, E., Tomsia, A. P. \& Cannon, R. M. Wetting and work of adhesion in oxide/metal systems. In Ceramic Microstructures: Control at the Atomic Level, eds. A. P. Tomsia, A. M. Glaeser, Plenum Press, New York,1998, pp. 65-82.

[6] Tomsia, A. P \& Pask, J. A. Chemical reactions and adherence at glass/metal interfaces: and anlysis. Dental Materials, 1986, 2, 10-16.

[7] Aksay, I. A., Dabbs, D. M. \& Sarikaya, M. J. Mullite for structural, electronic, and optical applications. J. Am. Ceram. Soc., 1991, 74, 2343-58.

[8] Hynes, A. P. \& Doremus, R. H. High-temperature compressive creep of polycrystalline mullite. J. Am. Ceram. Soc., 1991, 74, 2469-2475.

[9] Torrecillas, R., Calderón, J. M., Moya, J. S., Reece, M. J., Davies, C. K. L., Olagnon C. \& Fantozzi G. J. Suitability of mullite for high temperature applications, J. Eur. Ceram. Soc., 1999, 19, 2519-2527.

[10] Outokumpu HSC Chemistry for Windows, Outokumpu Research, Oy, Finland, 1993. 
[11] Baker, H., Benjamin, D., Kirkpatrick, C. W. \& Nieman, K., Metal Handbook, $9^{\text {th }}$ edn, Materials Park, OH: ASM International, 1979.

[12] Kumar, A. \& Eyre, B. L. Grain boundary segregation and intergranular fracture in molybdenum, Proc. R. Soc. Lond. A, 1980, 370, 431-458.

[13] Srivastava, S. C. \& Seigle, L. L. Solid Solubility of Oxygen in Molybdenum. 5th Spring Meeting of the Metallurgical Society of AIME. Metallurgical Soc. AIME. 1973, pp.124-5.

[14] Reimanis, I. E, Shinde, S. L \& De Jonghe, L. C. Evolution of the Nickel/Zirconia Interface, Ceram. Eng. Sci. Proc., 1989, 10, 1567.

[15] Davis, J. B., Yang, J. \& Evans, A. G. Effects of composite processing on the strength of sapphire fiber-reinforced composites, Acta Metal Mater, 43, 1995, 259-268. 


\section{Figure captions}

Figure 1. SEM micrographs of (a) monolithic mullite and (b) mullite- $\mathrm{MoO}_{2}$ composite, thermally etched at $1450^{\circ} \mathrm{C}$ in argon for 1 hour.

Figure 2. SEM images of the polished cross section perpendicular to the interface of (a) mullite/molybdenum and (b) mullite- $\mathrm{MoO}_{2} /$ molybdenum.

Figure 3. SEM micrograph showing a molybdenum oxide partially reduced grain in contact with the molybdenum foil (arrows).

Figure 4. SEM micrographs of Vickers indentation (50 kg load) and close-up of the mullite/molybdenum interface.

Figure 5. SEM micrographs of the fracture surface of: (A) mullite- $\mathrm{MoO}_{2} / \mathrm{Mo}$ specimen; (B) close-up of the metal side, in which marks of the grain boundaries of mullite on molybdenum foil are evident; $(\mathrm{C})$ close-up of the ceramic side, in which ridges having spacings comparable to the grain size in the metal can be observed; and (D) mullite/Mo specimen. 

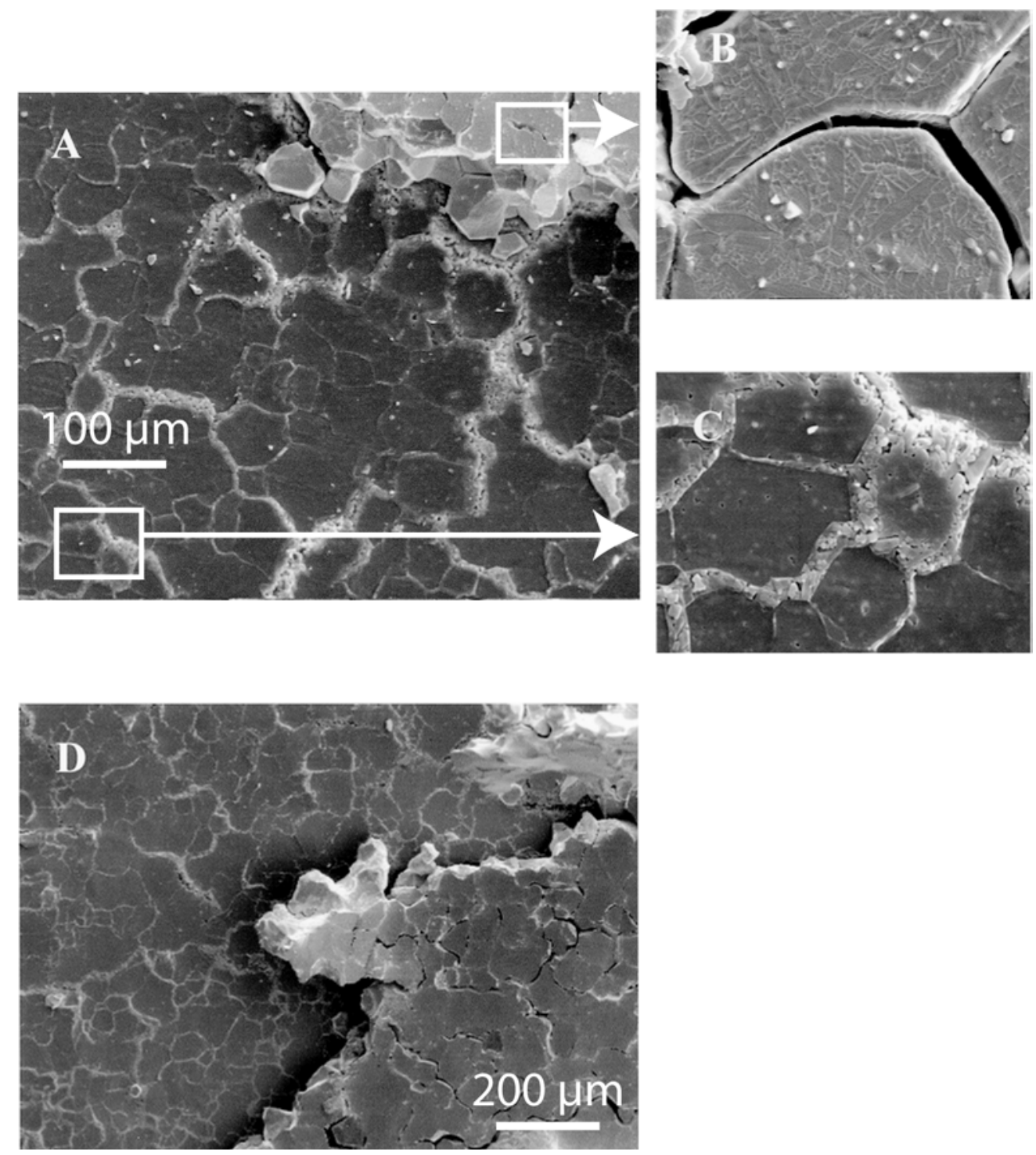

Figure 1 

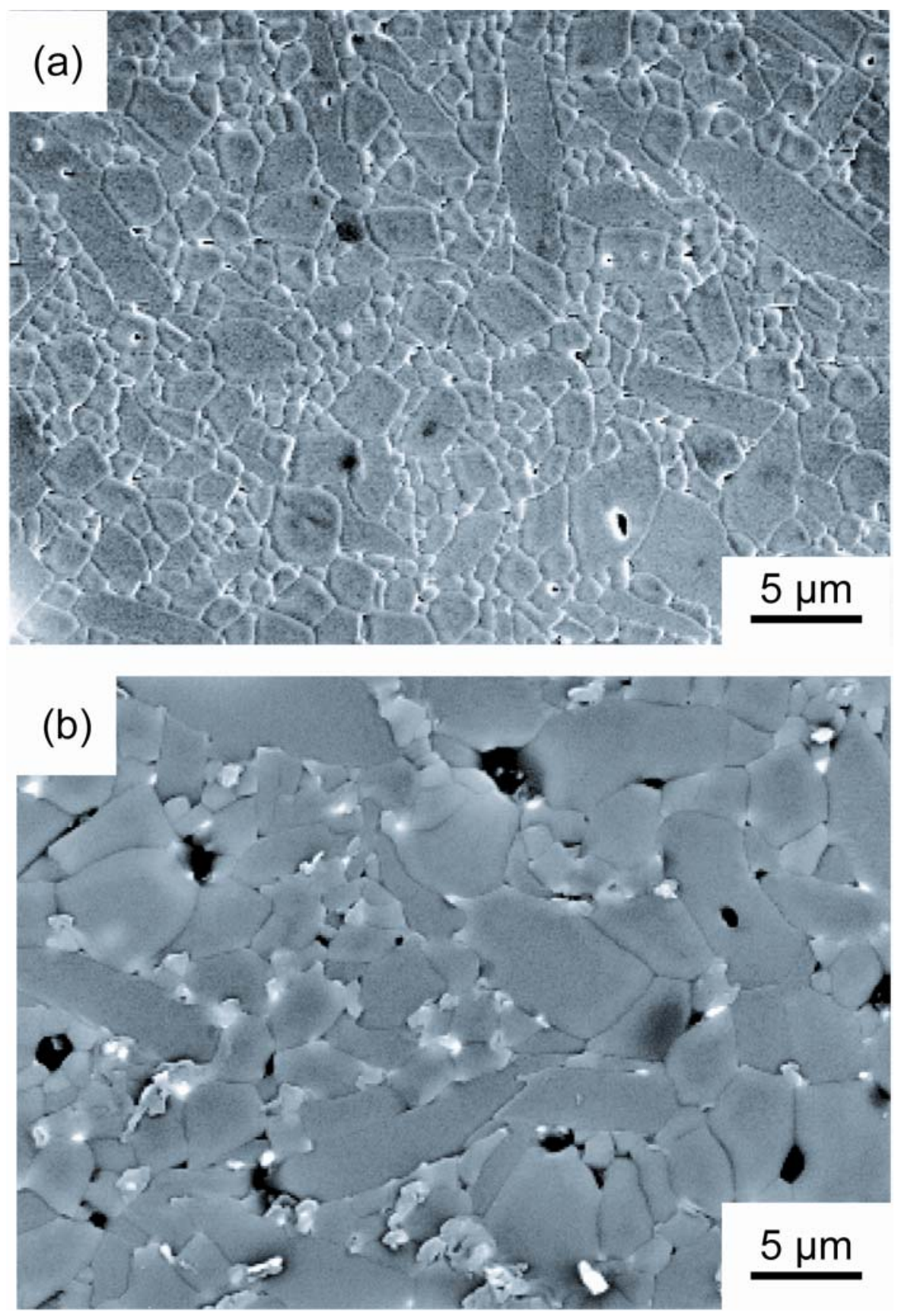

Figure 2 

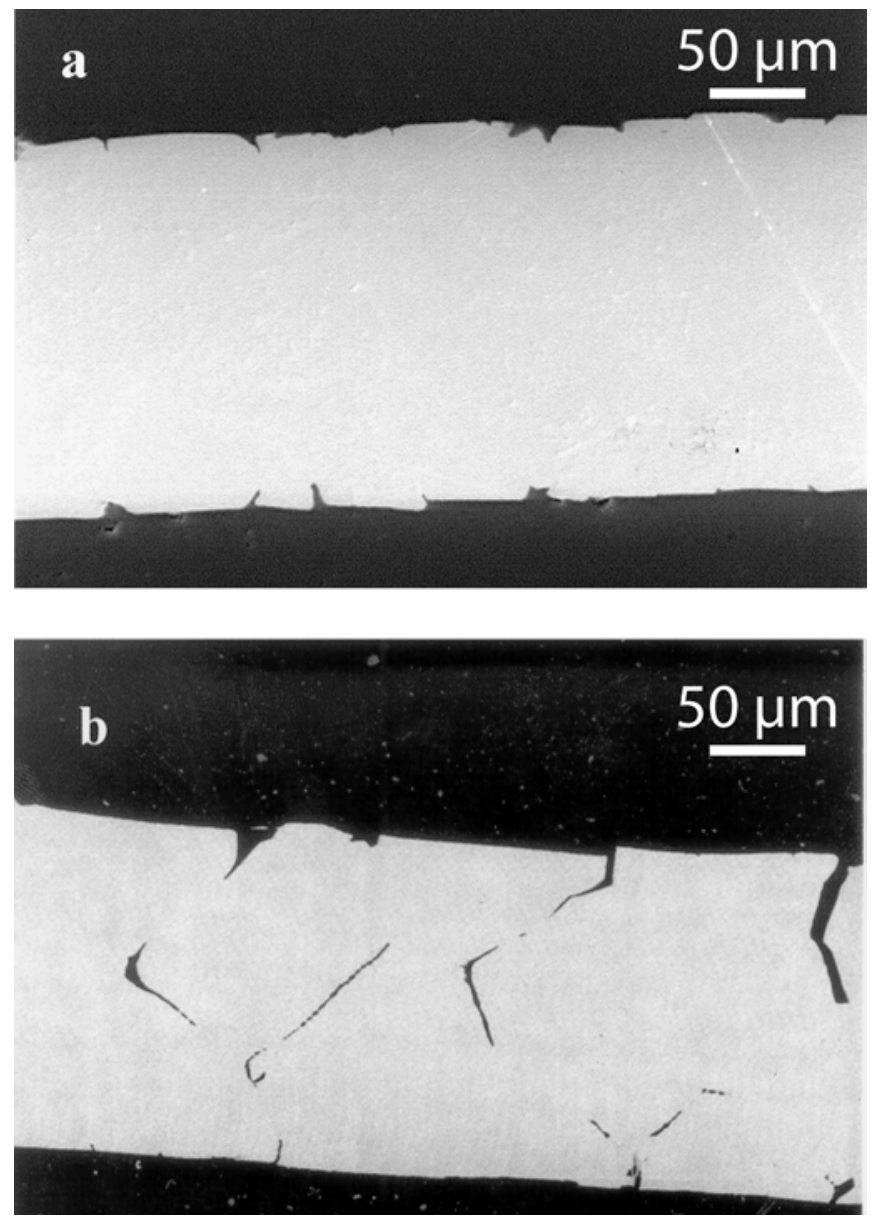

Figure 3

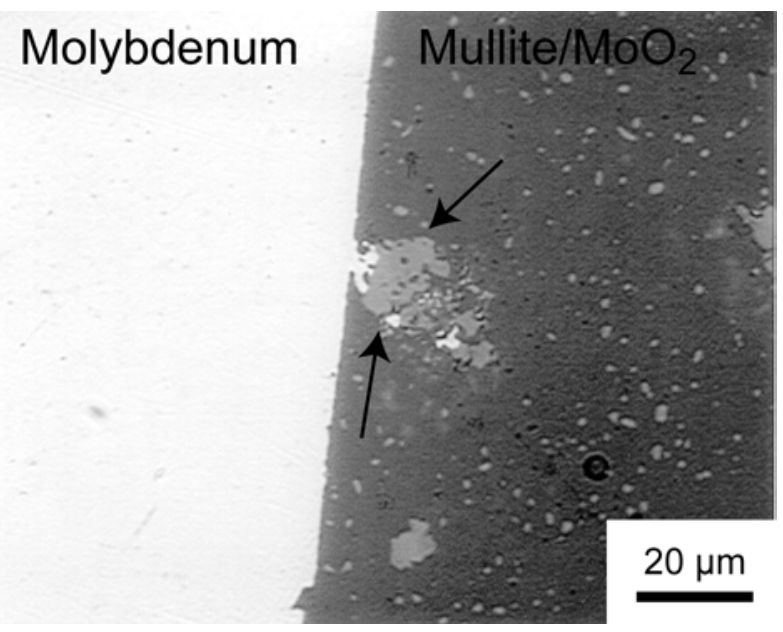

Figure 4 

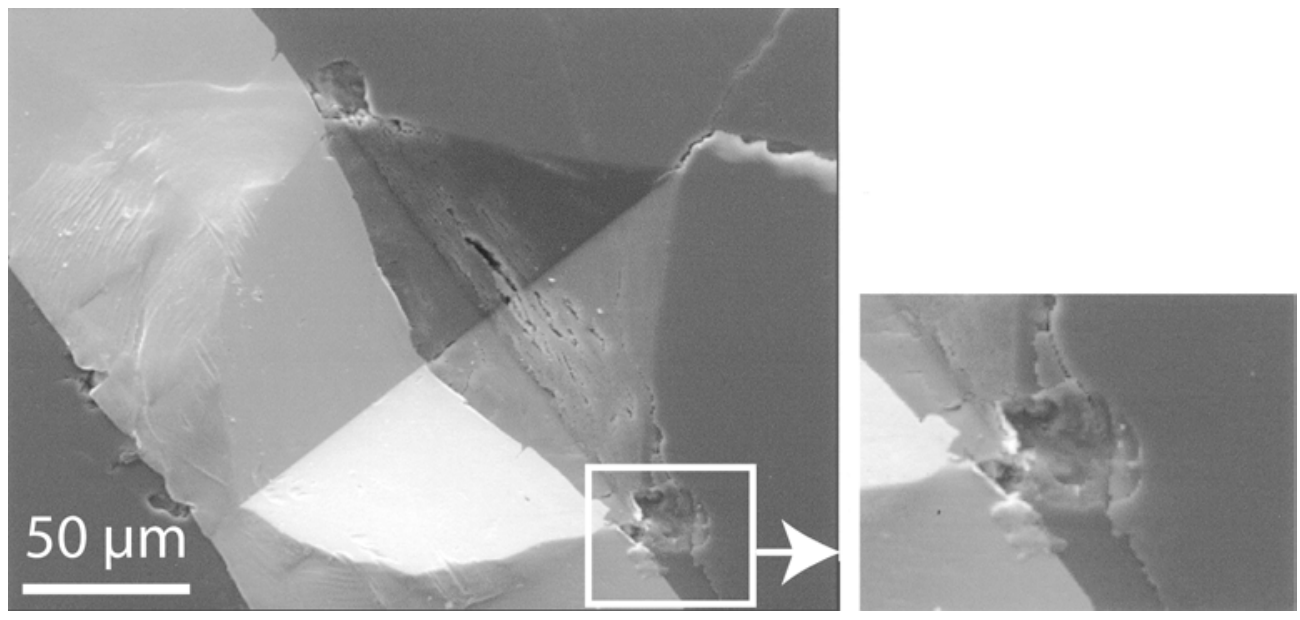

Figure 5 